Int. J. Environ. Res. Public Health 2007, 4(1), 53-60

International Journal of

Environmental Research and Public Health

ISSN 1661-7827

www.jijerph.org

(c) 2007 by MDPI

\title{
Class B Alkaline Stabilization to Achieve Pathogen Inactivation
}

\author{
Christine L. Bean ${ }^{1,3}$, Jacqueline J. Hansen ${ }^{1}$, Aaron B. Margolin ${ }^{1}$, Helene Balkin ${ }^{1}$, Glenda Batzer ${ }^{2,4}$, and Giovanni \\ Widmer $^{2} *$ \\ ${ }^{1}$ Department of Microbiology, University of New Hampshire, 35 Colovos Rd, ETB Hall Rm. 230, Durham, NH 03824, USA \\ ${ }^{2}$ Tufts Cummings School of Veterinary Medicine, Division of Infectious Diseases, North Grafton, Massachusetts 01536, USA \\ ${ }^{3}$ Public Health Laboratories, Department of Health and Human Services, 29 Hazen Drive, Concord, NH 03801, USA \\ ${ }^{4}$ University of California San Diego - School of Medicine, Stein CRB-126 BB, La Jolla, CA 92093, USA \\ "Correspondence to Dr. Giovanni Widmer. E-mail: giovanni.widmer@tufts.edu.
}

Received: 02 March 2007 / Accepted: 15 March 2007 / Published: 31 March 2007

\begin{abstract}
Liming is a cost-effective treatment currently employed in many Class B biosolids production plants in the United States. A bench scale model of lime stabilization was designed to evaluate the persistence of viral, bacterial and parasitic pathogens. The survival of fecal coliforms, Salmonella, adenovirus type 5, rotavirus Wa, bacteriophage MS-2, Cryptosporidium parvum oocysts, Giardia lamblia cysts, and Ascaris lumbricoides ova was evaluated under lime stabilization conditions in a water matrix. Fecal coliforms and Salmonella were undetectable following 2 hours of lime stabilization, demonstrating a 7-log reduction. Adenovirus, MS-2 and rotavirus were below detectable levels following 2 $\mathrm{h}$ of liming, demonstrating a 4-log reduction. G. lamblia cysts were also inactivated. A. lumbricoides ova remained viable following 72 hours of liming as did $C$. parvum oocysts. While this study confirmed that Ascaris ova are resistant to liming, their scarcity in sludge and low recovery efficiencies limit their use as indicator. The persistence of $C$. parvum oocysts after exposure to lime, suggests that this parasite would be a better choice as indicator for evaluating biosolids intended for land application. The studies done with adenovirus Type 5, rotavirus Wa and male specific bacteriophage provided preliminary data demonstrating similar inactivation rates. Monitoring anthropogenic viruses is a time consuming, labor intensive and expensive process. If further studies could demonstrate that phage could be used as an indicator of other enteric viruses, enhanced monitoring could result in greater acceptance of land application of biosolids while demonstrating no increased public health threat.
\end{abstract}

Keywords: Biosolids, alkaline stabilization, Ascaris lumbricoides, fecal coliforms, Cryptosporidium

\section{Introduction}

Biosolids are categorized as Class A or Class B. Class A biosolids contain pathogens below detectable levels whereas Class B sludge contains pathogens which are reduced in number. The requirements for use and disposal of biosolids depend on the classification. The use of lime to reduce or eliminate pathogen content in sewage sludge represents a simple and inexpensive treatment by which Class B sludge can be generated [1]. Lime stabilization is a process where calcium hydroxide $\left(\mathrm{Ca}(\mathrm{OH})_{2}\right)$ or calcium oxide $(\mathrm{CaO})$ is added and the $\mathrm{pH}$ elevated to 12 for 2 or more hours. Lime has been in use for a number of years for the disinfection and odor suppression of solid wastes.

Fecal coliform bacteria are used to indicate the potential presence of pathogens in biosolids [2]. With regard to biosolids and land application, Salmonella and other bacteria like Staphylococci, are of concern because the potential exists for re-growth following treatment [3-5]. The densities of fecal coliforms in sewage can be high [6]. The EPA Part 503 regulations ${ }^{7}$ require that fecal coliform density may not exceed one thousand most probable number (MPN) or colony forming units (CFU) per gram of solids if the sludge is to partially qualify as Class A sludge, or less than $2 \times 10^{6} \mathrm{MPN}$ or CFU per gram solids if the sludge is to qualify as Class B sludge under Alternative 1. These regulations also require that treated sewage sludge must be monitored for fecal coliforms or Salmonella species and have a Salmonella density of less than three most probable number (MPN) per 4 grams total solids to qualify as a Class A sludge.

Previous research to evaluate the persistence of poliovirus type 1 under lime stabilization conditions demonstrated that high $\mathrm{pH}$ is very effective at reducing or eliminating the viral load from sludge [8-11]. Currently, there is little information available on the removal and 
inactivation of human enteric pathogenic viruses, such as rotavirus and adenovirus, for which culture methods were not available when the original studies evaluating the effects of high-pH lime treatment of sewage were conducted. Rotaviruses have been detected in water, wastewater and more recently in biosolids, although very little data exists on their occurrence in biosolids [12]. These viruses are resistant to environmental conditions and are present in large amounts in wastewater [13, 14]. Adenoviruses are among the most common and persistent viruses in wastewater and have been transmitted by both, recreational and drinking water [15-17]. Information on the occurrence of enteric viruses in biosolids is primarily focused on the prevalence of poliovirus in biosolids, and the effect of treatment ${ }^{18}$, yet for many processes the amount of data on virus removal is limited. With the advent of new and improved cell culture techniques, it is now possible to assess prevalence and persistence of pathogens such as rotavirus and adenovirus that were previously not cultivatable. Bacteriophages have received a great deal of attention as indicator organisms due to their similarity in size and composition to enteroviruses [19], which suggests that they could represent a better model for the presence of pathogens and to assess inactivation by treatment processes. Currently, no data comparing the inactivation of bacteriophage and enteric virus during traditional sludge treatment processes is available.

Protozoan parasites include Giardia and Cryptosporidium, which cause acute gastrointestinal distress resulting in severe diarrhea and may lead to death in immunocompromised individuals [20, 21]. Cryptosporidium parvum is commonly found in surface water, is highly resistant to conventional methods of water treatment [22], and therefore may be a better candidate for the monitoring of human parasites in biosolids for treatment effectiveness.

Helminth ova are one of the pathogens utilized to indicate effective treatment of sewage sludge for land application [23]. Current EPA 503 regulations (Class A, Alternative 3 ) require sewage sludge to be screened for the presence of $A$. lumbricoides ova, however there is little data available to indicate the effects of lime stabilization on the viability of this nematode.

The goal of this investigation was to evaluate the survival of representative viral, bacterial and protozoal pathogens, as well as A. lumbricoides ova under conditions simulating lime stabilization. Whereas viruses, bacteria and $G$. lamblia cysts were readily inactivated, $C$. parvum oocysts and $A$. lumbricoides ova remained viable.

\section{Materials and Methods}

\section{Lime Treatments}

Lime treatments of viruses, bacteria and parasites were performed independently in $50-\mathrm{mL}$ volumes of $\mathrm{Ca}$ $(\mathrm{OH})_{2}$ solution. Bacteriophage was included in all lime experiments as an internal control. Adenovirus Type 5 and MS-2 were inoculated to achieve a final concentration of
$1.0 \times 10^{6}$ tissue culture infectious dose $50 \%\left(\mathrm{TCID}_{50}\right)$ and plaque forming units $(\mathrm{PFU}) / \mathrm{ml}$ respectively. The same experimental design was employed in separate trials with Rotavirus Wa and MS-2 at a starting concentration of $1.0 \mathrm{x}$ $10^{4} \mathrm{PFU} / \mathrm{ml}$ for each virus. G. lamblia cysts purified from experimentally infected gerbils were purchased from Waterborne Inc (New Orleans, LA). Oocysts from $C$. parvum were purified from the feces of experimentally infected mice as described [24]. C. parvum and G. lamblia were inoculated to achieve a final concentration of $10^{6}$ oocysts $(+/-5.1 \%)$ and $5 \times 10^{5}$ cysts (+/-3.9\%) per ml, respectively. Aliquots of 3,000 A. lumbricoides ova were resuspended in the matrix for both the control and the test samples. Samples were continually mixed on a stir plate and the initial $\mathrm{pH}$ and temperature recorded for control and test beakers. The $\mathrm{pH}$ of the test beakers was simultaneously adjusted to 12.0 using an $8 \%$ aqueous slurry comprised of calcium hydroxide and distilled deionized water. Approximately $0.4-0.5 \mathrm{~mL}$ of calcium hydroxide slurry was required to elevate the $\mathrm{pH}$ to 12.0 , corresponding to a lime dose of approximately $80 \mathrm{~g} / \mathrm{kg}$ total solids. The $\mathrm{pH}$ was maintained at 12.0 for 2 hours at which time, $0.1 \mathrm{~N}$ $\mathrm{HCl}$ was added drop by drop until a $\mathrm{pH}$ value of 11.5 was achieved and maintained for the duration of the experiment. This was done to emulate the alkaline stabilization practices that are currently employed in the State of New Hampshire. Experiments were performed at room temperature with temperature and $\mathrm{pH}$ readings recorded hourly for control and test beakers. The viability of bacteria, viral pathogens and phage were evaluated at time points $0.1,2,12$ and 24 hours. The infectivity of protozoan pathogens was evaluated at $0.1,2,12,24,48$, and 72 hours. Survival of helminth ova was evaluated at 24, 48 and 72 hours. Following lime stabilization, test beakers were neutralized with $0.1 \mathrm{~N} \mathrm{HCl}$ and aliquots were removed from designated control and test beakers for enumeration.

Aliquots of control and neutralized test sample were diluted in phosphate buffered saline and evaluated immediately for male specific bacteriophage using a double agar overlay technique [25]. Aliquots of control and neutralized test sample designated for viral enumeration were centrifuged for 10 minutes at $1000-\mathrm{x}$ g to remove precipitated lime. Following centrifugation, the supernatant was retained and assayed for adenovirus type 5 and rotavirus Wa by $\mathrm{TCID}_{50}$ and plaque assay respectively. Trials were performed at room temperature $\left(28^{\circ} \mathrm{C}\right)$ with temperature and $\mathrm{pH}$ readings recorded hourly for control and test beakers.

\section{Fecal Coliforms}

Fecal coliform densities in reverse osmosis (RO) water samples obtained following lime stabilization experiments were evaluated using a most probable number assay (MPN) according to method 1680, established by the EPA for fecal coliform detection in biosolids by multiple tube fermentation [26]. The MPN assay is an estimation of bacterial density and employs culture specific media 
combined with elevated temperature to isolate and enumerate fecal coliforms. A presumptive step using lauryl tryptose broth (LTB) (Difco) as the selective enrichment medium and a completed step using E. coli (EC) (Difco) media permit the recovery and isolation of fecal coliforms. Ten-fold serial dilutions were created and inoculated into 5 test tubes containing sterile LTB and a Durham fermentation tube to indicate gas production. Tubes were incubated for 48 hours at $35^{\circ} \mathrm{C}$ and observed at both 24 and 48 hours for the presence of presumptive growth indicated by gas or acid production in the fermentation tubes. Failure to produce gas or acid in the LTB media within 48 hours was recorded as a negative presumptive test. LTB presumptive positive tubes were transferred to fermentation tubes containing sterile EC media. EC fermentation tubes were incubated in a water bath at $44.5^{\circ} \mathrm{C}$ for 24 hours. Gas production in EC broth in 24 hours was considered a positive fecal coliform reaction. Failure to produce gas was a negative reaction and indicated fecal coliform bacteria were not present. Results of the MPN procedure were reported in terms of MPN/g total solids calculated from the number of positive EC culture tubes. Positive control cultures consisting of $E$. coli were included in each assay to ensure negative results were not from inhibition.

\section{Salmonella}

Salmonella densities following lime stabilization experiments were evaluated using a most probable number assay (MPN) according to method 1682 established by the EPA for Salmonella detection in biosolids by multiple tube fermentation [26]. Sample dilutions were created using phosphate buffered saline. Enrichment was accomplished using selenite brilliant green sulfa (SBG) broth followed by isolation on xylose-lysine deoxycholate agar (XLD). Positive samples were confirmed with triple sugar iron agar (TSI), lysine iron agar (LIA), and urease broth followed by positive serological typing using polyvalent antisera. Results of the MPN procedure were reported in terms of MPN/g total solids. Positive control cultures consisting of Salmonella typhimurium and negative control cultures consisting of $E$. coli were included in each assay to ensure negative results were not from inhibition.

\section{Male-Specific Bacteriophage MS-2}

Propagation and enumeration of the male-specific bacteriophage MS-2 was accomplished using an E. coli bacterial host harboring a conjugative plasmid that confers streptomycin and ampicillin resistance, and pilus production (E. coli $\mathrm{F}$. Amp HFR). This host was chosen for its antibiotic resistance, making it useful for studies involving sludge and wastewater, where the potential for contamination is very high. The host was grown to log phase in tryptic soy broth supplemented with $1 \%(100 x)$ streptomycin/ampicillin and 1\% magnesium chloride at $37^{\circ} \mathrm{C}$. MS-2 bacteriophage was added to the log phase $E$. coli culture and incubated at $37^{\circ} \mathrm{C}$. Following $12-18$ hours of incubation, the viral suspension was centrifuged at $10,000 \mathrm{rpm}\left(4^{\circ} \mathrm{C}\right)$ and the supernatant was collected and refrigerated at $4^{\circ} \mathrm{C}$ until use. Phage was enumerated using a modified double-agar-overlay procedure previously described [25]. A $0.1 \mathrm{~mL}$ portion of sample and $0.2 \mathrm{~mL}$ of $E$. coli were inoculated into $5 \mathrm{~mL}$ of a sterile tempered agar overlay and immediately poured onto a sterile tryptic soy agar plate. Plates were incubated at $37^{\circ} \mathrm{C}$ and observed 12 18 hours later for plaques. Plaques, characteristic zones of clearing in the agar overlay, were counted in the range of 30-300.

\section{Adenovirus}

Adenovirus Type 5 was propagated in A549 cells cultivated in Eagles minimal essential medium (MEM) (Sigma) supplemented with 5\% fetal bovine serum (FBS). A $0.25 \mathrm{~mL}$ portion of an appropriate inoculum of propagated virus was added to ten wells of a 96-well plate for enumeration using the $\mathrm{TCID}_{50}$ method established by Reed and Muench (1938). Inoculated cultures were incubated at $37^{\circ} \mathrm{C}$ in $5 \% \mathrm{CO}_{2}$ for 90 minutes with periodic rocking to prevent dehydration and promote maximum and uniform absorption of the virus. Following absorption, $0.15 \mathrm{~mL}$ of Eagles MEM maintenance medium supplemented with $2 \%$ fetal bovine serum was added to each well.

\section{Rotavirus}

Rotavirus Wa strain was propagated in Ma104 cells cultivated in Eagles MEM supplemented with 10\% FBS. Following infection, monolayers of Ma104 cells were maintained with Eagles MEM supplemented with five micrograms per $\mathrm{ml}$ of trypsin (GIBCO). Propagated virus was enumerated using a modified plaque-forming unit (PFU) method [27]. Cell culture plates with 12 wells of Ma104 cells were grown to confluency in 5\% percent $\mathrm{CO}_{2}$. A $0.1 \mathrm{~mL}$ portion of inoculum was added to each well in triplicate. Inoculated cultures were returned to $37^{\circ} \mathrm{C}$ in $5 \%$ $\mathrm{CO}_{2}$ for 60 minutes with periodic redistribution. Following adsorption, $2 \mathrm{ml}$ of an agar overlay maintenance medium consisting of $2 \mathrm{X}$ minimal essential medium supplemented with $1 \mu \mathrm{g} / \mathrm{ml}$ trypsin, and $2 \%$ agar (Sigma) was added and the plates returned to the $5 \% \mathrm{CO}_{2}$ incubator for four days at which time cells were fixed with $2 \mathrm{ml}$ of $10 \%$ formaldehyde in normal saline solution overnight. Overlay plugs were removed from wells by rinsing under warm tap water followed by the addition of $2 \mathrm{ml}$ of a $0.1 \%$ crystal violet solution. Excess crystal violet was removed and plaques counted. Each dilution was enumerated in triplicate and averaged. The viral titer was determined by multiplying the average number of plaques by the dilution factor.

\section{Cryptosporidium parvum}

C. parvum oocysts, Moredun (MD) isolate ${ }^{28}$, propagated in immunosuppressed mice ${ }^{29}$ were used 
throughout this study. Fecal pellets were collected from infected animals and homogenized in $10 \mathrm{ml}$ of water. Oocysts were purified by sedimenting on a step gradient of $15 \%-25 \% \quad(\mathrm{w} / \mathrm{v})$ Histodenz (N, N'-bis (2,3 dihydroxypropyl acetamido-2, 4,6-tri-iodo-isophthalamide) (Sigma) in water [24], brought to $50 \mathrm{ml}$ in water, and pelleted by centrifugation at $4000 \mathrm{x}$ g for $15 \mathrm{~min}$. Purified oocysts were resuspended in $1 \mathrm{ml}$ of water. Following lime stabilization, oocysts were neutralized to $\mathrm{pH} 7$ with $0.1 \mathrm{~N}$ $\mathrm{HCl}$, transferred to $50 \mathrm{ml}$ conical polypropylene centrifuge tubes, and precipitated by centrifugation at $4000 \mathrm{x}$ g for 15 min. Pellets were resuspended in $2 \mathrm{~mL}$ of RO water and the oocyst concentration determined with a hemocytometer in duplicate. In some experiments, the presence of $\left(\mathrm{Ca}(\mathrm{OH})_{2}\right)$ crystals interfered with obtaining accurate oocyst counts, making it necessary to immunofluorescently label the oocysts (Merifluor Cryptosporidium/Giardia, Meridian Bioscience Inc., Cincinnati, Ohio). Oocysts were then counted by epifluorescent microscopy.

Neonatal CD-1 mice 1-3 days of age (Charles River Laboratories, Wilmington, Mass.) were orally infected with oocysts suspended in water ${ }^{30}$. Infected and uninfected control mice were sacrificed on day 7 post-infection, the intestine removed and homogenized in $300 \mu$ phosphate buffered saline in a microcentrifuge tube. A portion of 10 $\mu l$ of intestinal slurry from each mouse was spread in each well of 10-well Teflon coated microscope slides and the samples air-dried. Oocysts were stained by immunofluorescence and detected by epifluorescence microscopy. Samples with a minimum of 1 immunofluorescently labeled oocyst were scored as positive. Positive control mice were infected with oocysts from the same stock as used for the treatments. Oocysts for the negative controls were heat-inactivated at $70^{\circ} \mathrm{C}$ for 20 $\min [31]$.

\section{Giardia lamblia}

Cysts of $G$. lamblia isolate $\mathrm{H} 3$ purified from experimentally infected gerbils were obtained from Waterborne, Inc., New Orleans, Louisiana. Cysts were purified on sucrose and Percoll density gradients and shipped in PBS supplemented with penicillin, streptomycin $(500 \mathrm{U} / \mathrm{ml}$ each) and gentamycin $(50 \mathrm{~g} / \mathrm{ml})$.

To assess the infectivity of the cysts, Mongolian gerbils (4-wk-old, Charles River, Wilmington, Massachusetts) were each orally infected with a $20 \mu \mathrm{l}$ suspension of 1000 cysts (first experiment) or 500 cysts (second experiment) as described [32]. Groups of 8 animals were used for each treatment. Fecal pellets were collected from the gerbils on day $6,8,10,12$, and 14 postinfection. The presence of $G$. lamblia cysts in the feces was monitored by immunofluorescence using the Merifluor Cryptosporidium/Giardia kit (Meridian Diagnostics, Cincinnati, Ohio) as described [33]. Fecal samples were scored as positive if a minimum of 1 immunolabelled cyst was detected.

\section{Ascaris lumbricoides}

Viable ova were purchased from Tropical Biologicals (Guaynabo, Puerto Rico). These originated from human fecal samples collected in the Dominican Republic. Ova were received in a suspension of $2 \%$ formol to inhibit microbial growth. The suspension was stored at $20^{\circ}-23^{\circ} \mathrm{C}$ and aerated daily by removing the lid to exchange the air inside, replacing the lid and shaking 4-5 times. Storage of ova for more than two weeks required decanting the supernatant and replacing with fresh $2 \%$ formol every 2-3 weeks. Viability of ova was assessed prior to use following the EPA Part 503 method. Lime treatment and neutralization was performed as described for $C$. parvum. The entire test and control volumes were centrifuged at $1000 \mathrm{x}$ g for 10 min. The supernatant was decanted and the pellet resuspended in $10 \mathrm{~mL}$ of $\mathrm{RO}$ water. Portions of $1 \mathrm{ml}$ were screened using Sedgwick-rafter counting chambers under 10x magnification. Viability was determined by observing motile larva in embryonated ova under 40x magnification. One hundred ova were evaluated for each time point.

\section{Data Analysis}

Statistical analysis of treatment effectiveness for bacteria and virus was conducted using a general linear model within the SPSS statistical software package. Percent viability was calculated for helminth ova test and control samples and the difference was used to determine overall treatment effectiveness. Bacteriophage was included in each experiment as an internal control. ANOVA analysis of the treatment inactivation of bacteriophage was used to assist in making comparisons between trials for individual organisms and trials between classes of organisms. Infectious dose $50 \%\left(\mathrm{ID}_{50}\right)$ values for C. parvum were calculated according to Reed and Muench (1938) and Finch et al.(1993).

\section{Results}

Bacteria

The results of three trials conducted with fecal coliforms (E. coli), Salmonella sp. and MS-2, spiked into a limed water matrix at room temperature are presented in Fig. 1. In two trials, following 0.1 hours of liming, E. coli concentrations were below detectable levels $(<1 \mathrm{MPN} / \mathrm{ml})$. In one trial, the concentration of fecal coliforms following initial liming (0.1 hours) was $6.0 \times 10^{5} \mathrm{MPN} / \mathrm{ml}$. In this trial, fecal coliform concentration were below detectable levels following 2 hours of liming at $\mathrm{pH} 12$. This data point was considered an outlier and was not included in the statistical analysis. In all trials, Salmonella sp. concentrations were below detectable levels $(<3 \mathrm{MPN} / \mathrm{ml})$ at all time points. Hence, there was a significant effect of liming on fecal coliforms, Salmonella and MS-2 in all trials $(\mathrm{p}$ value $=0.000)$. 


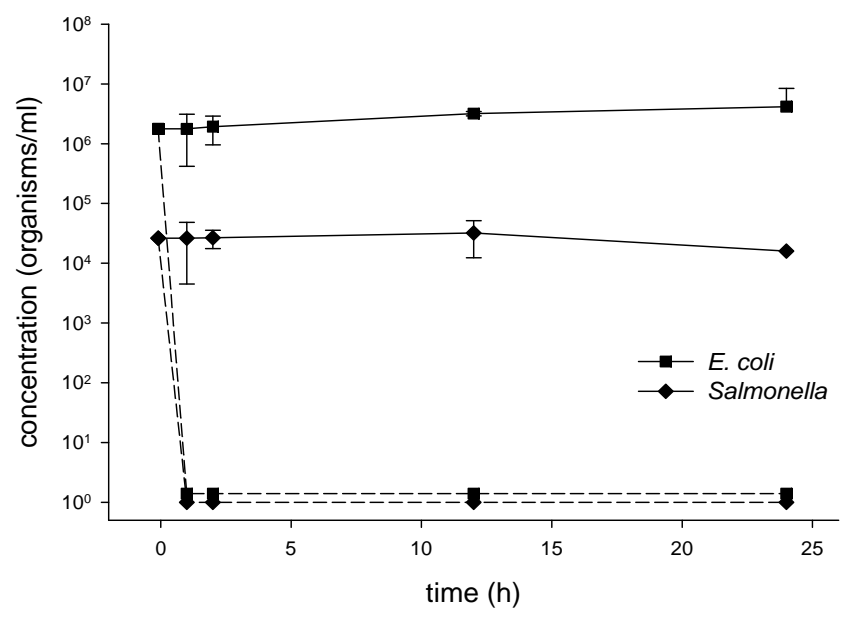

Figure 1: E. coli and Salmonella inactivation by liming stabilization. Results are from three replicate experiments at $28^{\circ} \mathrm{C}$. Following a $0.1 \mathrm{~h}$ period of liming E. coli counts were reduced by 6 logs and Salmonella sp. was below detectable levels, demonstrating at least a 4-log reduction. Bacterial concentrations of $10^{\circ}$ were artificially separated for clarity. Means and standard deviations are shown. Continuous lines represent untreated controls, dashed lines treatments.

\section{Virus}

The results of three trials conducted in a limed water matrix at $28^{\circ} \mathrm{C}$ with adenovirus type 5 , MS-2, and rotavirus are presented in Fig. 2. In all trials, adenovirus was below detectable levels by $\mathrm{TCID}_{50}$ following a 6-min exposure, indicating complete inactivation. Similarly, MS-2 and rotavirus were below detectable levels $(<1 \mathrm{PFU} / \mathrm{mL})$ in the same time period.

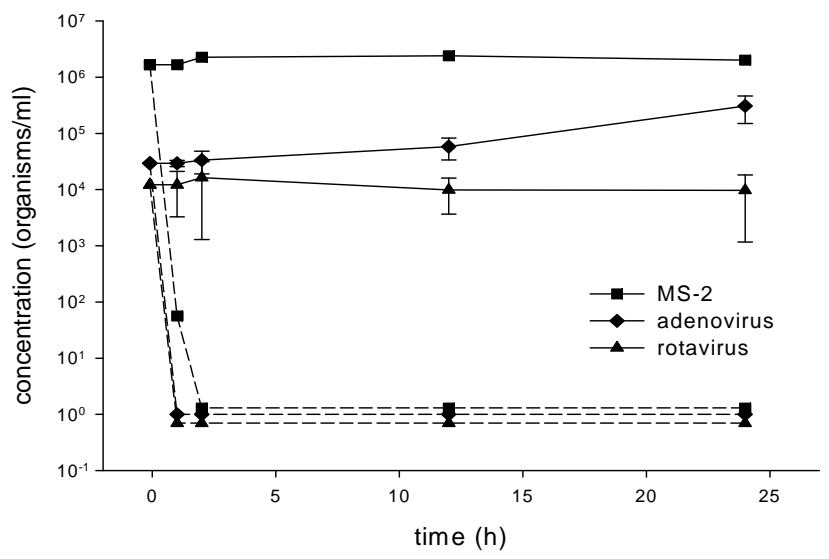

Figure 2: Adenovirus Type 5 and MS-2 inactivation in three replicate experiments conducted in limed water at room temperature. MS-2 was below detectable levels following $2 \mathrm{~h}$ of liming demonstrating at least 6-log reduction. Adenovirus and rotavirus was below detectable levels following lime stabilization for $6 \mathrm{~min}$, demonstrating 4-log reduction. Continuous lines show untreated controls, dashed lines treatments.
The treatment effect on adenovirus, rotavirus $\mathrm{Wa}$ and MS-2 was significant $(\mathrm{p}<0.001)$ and both viruses were below detectable levels following $6 \mathrm{~min}$ of liming. ANOVA of differences in treatment effectiveness for inactivation of adenovirus, MS-2 and rotavirus indicates that there was no significant difference between viruses.

\section{Cryptosporidium parvum}

Oocyst concentrations in control and treated samples dropped significantly during the experiment. The average reduction $(\mathrm{n}=3)$ in oocyst concentration was $74.2 \%$ $( \pm 18.8 \%)$ for the controls and $81.7 \%( \pm 29.9 \%)$ for the treatments $(2 \mathrm{hr}$ and $24 \mathrm{hr}$ treatments pooled). The reduction in oocyst concentration was not related to the treatment, since the difference between mock treatment and the actual treatment was statistically not significant ( $\mathrm{p}=0.75$, paired $t$-test), nor was it related to the duration of the exposure ( $2 \mathrm{hr}$ vs. $24 \mathrm{hr}, \mathrm{p}=0.41, t$-test). The reason for the loss in oocysts was not investigated, but is likely to have resulted from the adherence of oocysts to glass and plastic surfaces and incomplete recovery during centrifugation.

To assess the effect of liming on C. parvum oocysts, single-dose experiments were performed with oocysts exposed to lime solution for 0-72 hr. Immunofluorescence analysis of the intestinal homogenates recovered 7 day post-infection from mice infected with limed oocysts demonstrated that the treatments did not inactivate the oocysts. Infectious oocysts were detected in all samples, including those treated for $72 \mathrm{~h}$.
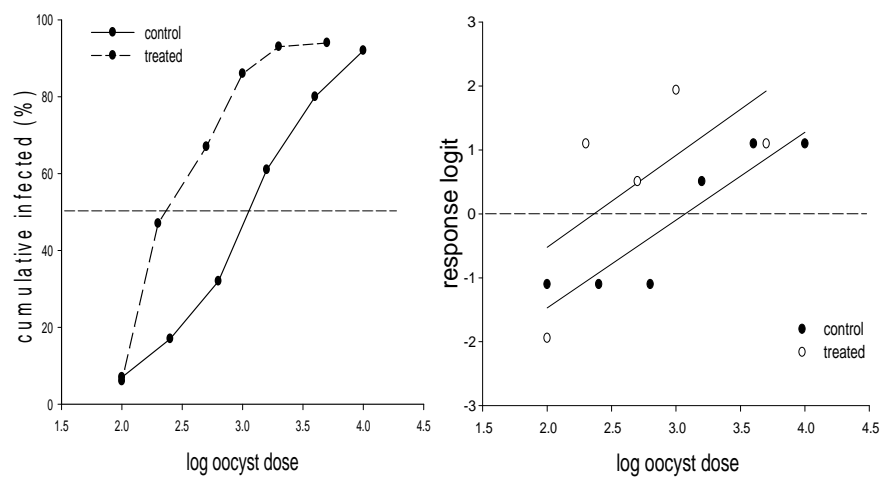

Figure 3: Inactivation of $C$. parvum oocysts with lime. Dose-response curves were obtained using the cumulative method ${ }^{37}$ (left) and the logit method ${ }^{38}$ (right). The 50\% cumulative infection and 0 logit used for determining the $\mathrm{ID}_{50}$ values are shown with dashed horizontal lines. Note the increase in oocyst infectivity (lower $\mathrm{ID}_{50}$ ) in response to treatment.

The infectivity of oocysts treated with lime for $2 \mathrm{~h}$ and $24 \mathrm{~h}$ was compared with that of mock-treated control oocysts using dose-response experiments. Groups of 8 neonatal mice were infected with 6 oocyst doses ranging 
from $10^{2}$ to $10^{4}$ oocysts. The infection was assessed 7 days post-infection. A positive control group was infected with 5000 oocysts per mouse pup and a negative control group received the same number of heat-inactivated oocysts. Fig. 3 shows the results obtained with oocysts exposed for $24 \mathrm{~h}$. Analysis of the dose-response experiment with the cumulative method and the logit method (Finch, 1993) both showed that lime stabilization for $24 \mathrm{~h}$ did not inactivate the oocysts. To the contrary, the treatment increased the infectivity of the oocysts by more than 4fold. Whereas the calculated $\mathrm{ID}_{50}$ for the untreated oocysts was 1180 , the $\mathrm{ID}_{50}$ for the treated oocysts was only 263 oocysts. A similar effect was observed after a 2-h exposure; the $\mathrm{ID}_{50}$ for the control oocysts was 986 and for the treated sample, 128 oocysts, a more than 7-fold reduction in $\mathrm{ID}_{50}$.

\section{Giardia lamblia}

Single-dose experiments in gerbils were performed to assess the inactivation of $G$. lamblia cysts exposed to lime solution for $0 \mathrm{~h}, 24 \mathrm{~h}, 48 \mathrm{~h}$ and $72 \mathrm{~h}$. In the first liming experiment, cysts were suspended in water. A second experiment was performed using sludge. In contrast to $C$. parvum, limed cysts were completely inactivated in $48 \mathrm{~h}$ or $72 \mathrm{~h}$. Following a 24-h exposure, infectious cysts were still detected, as demonstrated by the presence on day 10 postinfection of 2 positive gerbils in a group of 8 . None of the 8 gerbils infected with cysts exposed to lime for $48 \mathrm{hr}$ and $72 \mathrm{hr}$ excreted cysts between day 6 and day 14 postinfection, consistent with complete inactivation. All positive control animals inoculated with untreated cysts became infected, whereas 2 animals infected with heatinactivated cysts (negative control) remained negative until day 14 post-infection, when the experiment was terminated. Mock treatments, during which cysts were subjected to the same conditions as the treated cysts, except that no lime was added to the cyst suspension, slightly reduced cyst infectivity at $24 \mathrm{hr}, 48 \mathrm{hr}$ and $72 \mathrm{hr}$ as compared to the positive control group. The proportion of positive gerbils in these mock control groups was $8 / 8,7 / 8$, $5 / 8$ and $7 / 8$ for $0 \mathrm{~h}, 24 \mathrm{~h}, 48 \mathrm{~h}$, and $72 \mathrm{~h}$ mock treatment, respectively.

In a second experiment liming was performed in sludge instead of water. This experiment confirmed the inactivating effect of lime. Lime treatments for $24 \mathrm{hr}, 48$ $\mathrm{hr}$, and $72 \mathrm{hr}$ resulted in complete cyst inactivation; whereas the $0-\mathrm{h}$ treated and all the mock treated treatment groups infected all animals (8/8).

\section{Ascaris lumbricoides}

The results of two trials conducted with $A$. lumbricoides ova spiked into a limed water matrix at room temperature are presented in Fig. 4. In both trials ova in test samples remained viable following 72 hours of liming at room temperature. There was no significant difference between viability of control and test samples at all time points.

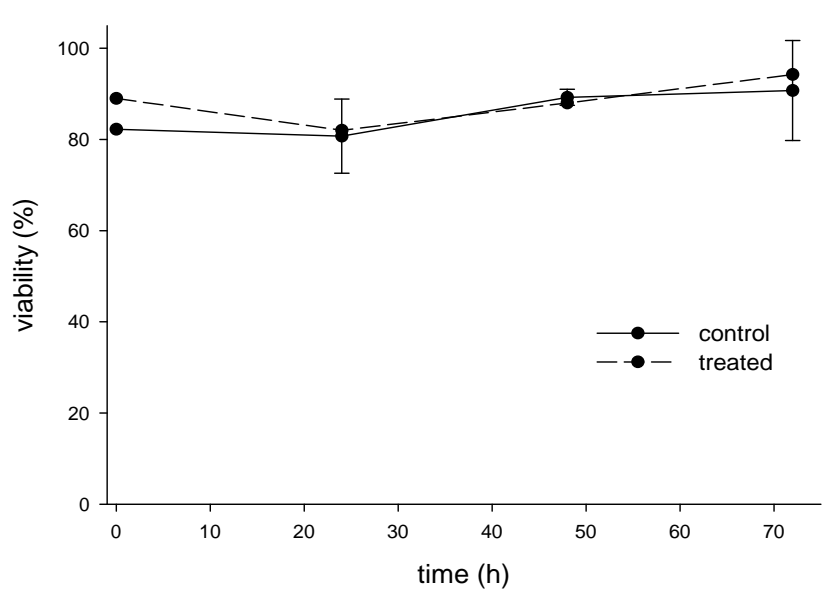

Figure 4: Resistance of A. lumbricoides ova to lime stabilization. Shown are mean and standard deviation from two replicate experiments conducted in limed water at $28^{\circ} \mathrm{C}$. Continuous line show untreated control, dashed line treatment.

\section{Discussion}

The goal of this study was to evaluate the persistence of fecal coliforms, Salmonella sp., enteric virus, bacteriophage, protozoa cyst and oocysts, and helminth ova under lime stabilization conditions. Organisms were evaluated in an RO water matrix, a best-case scenario for killing pathogens since it has been shown that organic material and particulate matter enhance the survival of microorganisms. Lime stabilization was very effectively in inactivating fecal coliforms, Salmonella, adenovirus, rotavirus, bacteriophage MS-2, and G. lamblia cysts, whereas $C$. parvum oocysts and A. lumbricoides ova were not significantly affected by lime stabilization. In an accompanying paper [34], the effect of liming viruses in water and sludge was compared. In both matrices adenovirus and MS2 was inactivated, albeit complete inactivation in sludge required more time.

Fecal coliforms are currently used as the microbiological parameter for Class B, Alternative 1 certification. These experiments demonstrate that fecal coliforms cannot be used as an indicator of treatment effectiveness for all pathogens, including Salmonella. Salmonella, an indicator organism for Class A certification, showed a similar rate of inactivation as $E$. coli. Thus indicating that bacterial organisms in these experiments behave similarly and are effectively inactivated when exposed to lime in a water matrix. In addition to Salmonella or fecal coliforms, enteric viruses and viable helminth ova are also parameters evaluated for Class A, Alternative 3 and Alternative 4 certification.

Enteric viruses are of particular importance with regard to land application of biosolids due to the potential for runoff resulting in surface water contamination and the potential for viral movement through the soil column into underground aquifers. Such movement is enhanced during 
a rain event where the cation binding of viruses to soil particulates is reduced and will vary with soil composition. Future studies to evaluate the persistence of virus in sludge and biosolids are necessary to determine the nature and impact of particle association on the treatment effectiveness of lime stabilization.

In addition to serving as an internal control, MS-2 was included because it is a potential indicator organism of treatment effectiveness. Bacteriophage is normally present in wastewater and as a result accumulates in sludge. Due to the high concentration of bacteriophage in sludge, along with its similar morphology to enteric virus, this organism is a potential indicator for assessing viral response to treatment. Because particle association takes place between charged viruses and soil particles, it is difficult to separate the viruses from the solid component for assay. As a result, routine monitoring of enteric virus from biosolids samples generally fails to recover enteric virus, erroneously indicating that the material is in compliance with regulations and suitable for land application. Survey of bacteriophage, which is easily recovered from sludge and biosolids matrices, may provide a screening tool to be used in conjunction with monitoring of endogenous enteric virus.

Although A. lumbricoides ova are not consistently present in biosolid, they are the current indicator for treatment effectiveness for Class A certification. An additional drawback of this indicator is the inefficient recovery ${ }^{35,36}$. While our study shows that ova are resistant to liming, their scarcity in sludge and low recoveries ${ }^{36}$ limit their use as an indicator. For these reasons, protozoa, which are ubiquitous in the environment and found more frequently than $A$. lumbricoides, were included in this investigation. The results demonstrate viability of $A$. lumbricoides ova following 72 hours of liming. In comparison, $C$. parvum evaluated under the same conditions demonstrated enhanced infectivity as a result of exposure to lime.

In conclusion, of relevance to the land application of biosolids, we found that lime stabilization in laboratory conditions effectively reduces bacterial and viral pathogens as well as $G$. lamblia cysts, but does not reduce the infectivity of $C$. parvum oocyst and A. lumbricoides ova. Further investigation to assess the effect of lime stabilization in a solid matrix is clearly warranted.

Acknowledgements: Funding from the Water Environment Research Foundation (grant RFP 99-HHE-3) is gratefully acknowledged.

\section{References}

1. Farrell, J. B.; Smith, J. E., Jr.; Hathaway, S. W.; Dean, R. B.: Lime stabilization of primary sludges. $J$ Water Pollut Control Fed 1974, 46, (1), 113-22.

2. Qi, Y. N.; Gillow, S.; Herson, D. S.; Dentel, S. K.: Reactivation and/or growth of fecal coliform bacteria during centrifugal dewatering of anaerobically digested biosolids. Water Sci Technol 2004, 50, (9), $115-20$.

3. Sidhu, J.; Gibbs, R. A.; Ho, G. E.; Unkovich, I.: Selection of Salmonella typhimurium as an indicator for pathogen regrowth potential in composted biosolids. Lett Appl Microbiol 1999, 29, (5), 303-7.

4. Zaleski, K. J.; Josephson, K. L.; Gerba, C. P.; Pepper, I. $\mathrm{L} .:$ Potential regrowth and recolonization of salmonellae and indicators in biosolids and biosolid-amended soil. Appl Environ Microbiol 2005, 71, (7), 3701-8.

5. Russ, C. F.; Yanko, W. A., Factors affecting salmonella's repopulation in composted sludges. Appl Environ Microbiol 1981, 41, (3), 597-602.

6. Hussong, D.; Burge, W. D.; Enkiri, N. K.: Occurrence, growth, and suppression of salmonellae in composted sewage sludge. Appl Environ Microbiol 1985, 50, (4), 887-93.

7. Epand, R. M.: Detecting the presence of membrane domains using DSC. Biophys Chem, 2006.

8. Sattar, S. A.; Ramia, S.; Westwood, J. C., Calcium hydroxide (lime) and the elimination of human pathogenic viruses from sewage: studies with experimentally-contaminated (poliovirus type 1, Sabin) and pilot plant samples. Can J Public Health 1976, 67, (3), 221-5.

9. Derbyshire, J. B.; Brown, E. G.: The inactivation of viruses in cattle and pig slurry by aeration or treatment with calcium hydroxide. J Hyg (Lond) 1979, 82, (2), 293-9.

10. Deng, M. Y.; Cliver, D. O.: Inactivation of poliovirus type 1 in mixed human and swine wastes and by bacteria from swine manure. Appl Environ Microbiol 1992, 58, (6), 2016-21.

11. Grabow, W. O.; Middendorff, I. G.; Basson, N. C.: Role of lime treatment in the removal of bacteria, enteric viruses, and coliphages in a wastewater reclamation plant. Appl Environ Microbiol., 1978, 35, (4), 663-9.

12. Chapron, C. D.; Ballester, N. A.; Fontaine, J. H.; Frades, C. N.; Margolin, A. B.: Detection of astroviruses, enteroviruses, and adenovirus types 40 and 41 in surface waters collected and evaluated by the information collection rule and an integrated cell culture-nested PCR procedure. Appl Environ Microbiol., 2000, 66, (6), 2520-5.

13. Keswick, B. H.; Gerba, C. P.; DuPont, H. L.; Rose, J. B., Detection of enteric viruses in treated drinking water. Appl Environ Microbiol., 1984, 47(6), 1290-4.

14. Estes, M. K.; Kang, G.; Zeng, C. Q.; Crawford, S. E.; Ciarlet, M., Pathogenesis of rotavirus gastroenteritis. Novartis Found Symp., 2001, 238, 82-96; discussion 96-100.

15. Gerba, C. P.; Pepper, I. L.; Whitehead, L. F.: 3rd, A risk assessment of emerging pathogens of concern in the land application of biosolids. Water Sci Technol 2002, 46, (10), 225-30.

16. Kukkula, M.; Arstila, P.; Klossner, M. L.; Maunula, L.; Bonsdorff, C. H.; Jaatinen, P., Waterborne 
outbreak of viral gastroenteritis. Scand J Infect Dis., 1997, 29, (4), 415-8.

17. Papapetropoulou, M.; Vantarakis, A. C., Detection of adenovirus outbreak at a municipal swimming pool by nested PCR amplification. J. Infect, 1998, 36, (1), 101-3.

18. Aitken, M. D.; Sobsey, M. D.; Blauth, K. E.; Shehee, M.; Crunk, P. L.; Walters, G. W.: Inactivation of Ascaris suum and poliovirus in biosolids under thermophilic anaerobic digestion conditions. Environ Sci Technol., 2005, 39, (15), 5804-9.

19. Bosch, A.: Human enteric viruses in the water environment: a minireview. Int Microbiol 1998, 1, (3), 191-6.

20. Griffiths, J. K.: Human cryptosporidiosis: epidemiology, transmission, clinical disease, treatment, and diagnosis. Adv Parasitol, 1998, 40, 37-85.

21. Guerrant, R. L., Cryptosporidiosis: an emerging, highly infectious threat. Emerg Infect Dis, 1997, 3, (1), 51-7.

22. Korich, D. G.; Mead, J. R.; Madore, M. S.; Sinclair, N. A.; Sterling, C. R., Effects of ozone, chlorine dioxide, chlorine, and monochloramine on Cryptosporidium parvum oocyst viability. Appl Environ Microbiol., 1990, 56, (5), 1423-8.

23. Capizzi-Banas, S.; Deloge, M.; Remy, M.; Schwartzbrod, J.: Liming as an advanced treatment for sludge sanitisation: helminth eggs elimination-Ascaris eggs as model. Water Res., 2004, 38, (14-15), 3251-8.

24. Widmer, G.; Tzipori, S.; Fichtenbaum, C. J.; Griffiths, J. K., Genotypic and phenotypic characterization of Cryptosporidium parvum isolates from people with AIDS. J. Infect Dis., 1998, 178, (3), 834-40.

25. Debartolomeis, J.; Cabelli, V. J.: Evaluation of an Escherichia coli host strain for enumeration of $\mathrm{F}$ male-specific bacteriophages. Appl Environ Microbiol., 1991, 57, (5), 1301-5.

26. Epand, R. F.; Thomas, A.; Brasseur, R.; Vishwanathan, S. A.; Hunter, E.; Epand, R. M.: Juxtamembrane protein segments that contribute to recruitment of cholesterol into domains. Biochemistry 2006, 45, (19), 6105-14.
27. Dulbecco, R.; Vogt, M., Plaque formation and isolation of pure lines with poliomyelitis viruses. $J$ Exp Med., 1954, 99, (2), 167-82.

28. Okhuysen, P. C.; Rich, S. M.; Chappell, C. L.; Grimes, K. A.; Widmer, G.; Feng, X.; Tzipori, S.: Infectivity of a Cryptosporidium parvum isolate of cervine origin for healthy adults and interferon-gamma knockout mice. $J$. Infect Dis., 2002, 185, (9), 1320-5.

29. Yang, S.; Healey, M. C.; Du, C., Infectivity of preserved Cryptosporidium parvum oocysts for immunosuppressed adult mice. FEMS Immunol Med Microbiol., 1996, 13, (2), 141-5.

30. Tzipori, S.: Cryptosporidiosis: laboratory investigations and chemotherapy. Adv Parasitol 1998, 40, 187-221.

31. Fayer, R., Effect of high temperature on infectivity of Cryptosporidium parvum oocysts in water. Appl Environ Microbiol., 1994, 60, (8), 2732-5.

32. Garcia, A.; Yanko, W.; Batzer, G.; Widmer, G., Giardia cysts in tertiary-treated wastewater effluents: are they infective? Water Environ Res 2002, 74, (6), 541-4.

33. Widmer, G.; Clancy, T.; Ward, H. D.; Miller, D.; Batzer, G. M.; Pearson, C. B.; Bukhari, Z., Structural and biochemical alterations in Giardia lamblia cysts exposed to ozone. J. Parasitol., 2002, 88, (6), 1100-6.

34. Hansen, M. S., Warden, P.S., and Margolin, A.B., Inactivation of adenovirus type 5, rotavirus WA and male specific coliphage (MS2) in biosolids by lime stabilization (submitted).

35. Bean, C. L.; Armstrong, M. J.; Galloway, S. M., Effect of sampling time on chromosome aberration yield for 7 chemicals in Chinese hamster ovary cells. Mutat Res., 1992, 265, (1), 31-44.

36. Bean, C. L.; Galloway, S. M.: Evaluation of the need for a late harvest time in the assay for chromosome aberrations in Chinese hamster ovary cells. Mutat Res., 1993, 292, (1), 3-16.

37. Reed, L. J., Muench H, A simple method of estimating fifty per cent endpoints. American Journal of Hygiene, 1938, 27, (3), 493-497.

38. Finch, G. R.; Daniels, C. W.; Black, E. K.; Schaefer, F. W., 3rd; Belosevic, M., Dose response of Cryptosporidium parvum in outbred neonatal CD-1 mice. Appl Environ Microbiol., 1993, 59, (11), 3661-5. 